\title{
DAUN KOPASANDA SEBAGAI TANAMAN ALTERNATIF PENANGKAL RADIKAL BEBAS
}

\author{
St. Maryam ${ }^{1}$, Widyawati², Uni Angreni Putri ${ }^{3}$, Dian Lestari ${ }^{4}$ \\ Email : st.maryam@umi.ac.id \\ 1,2,3,4 Fakultas Farmasi Universitas Muslim Indonesia, Indonesia
}

\section{ABSTRACT}

Kopasanda leaves (Chromolaena folium) are rich in flavonoids, including polyphenolic compounds that are closely related as substances that have the antioxidant capacity to ward off free radicals. Polyphenols in kopasanda include catechins, epicatechins, procyanidins and anthocyanidins. Kopasanda contains total phenols and a higher antioxidant capacity than wine or tea. So it is said that Kopasanda has high levels of antioxidants. The total antioxidant potential of the sample is determined by the ability to reduce iron ( $\mathrm{Fe}$ ) as a measure of "antioxidant strength". This study aims to examine the antioxidant activity and levels of flavonoid compounds in kopasanda leaves (Chromolaena folium), which will be analyzed using the FRAP method. The FRAP test was carried out by changing the blue color of FeII, a colorless tripyridyltriazine compound from FeIII that works to donate electrons. This method is widely used to analyze and determine the levels of antioxidants and flavonoid compounds in a plant. In the test, the absorbance results and the standard concentration of quercetin as a standard for antioxidant levels, from the linear regression results obtained the average value of the ethanol extract sample of kopasanda leaf (Chromolaena folium) of $16.914 \mathrm{mgQE} / \mathrm{g}$ extracts, meaning that in each gram of extract it is equivalent to $16.914 \mathrm{mg}$ quercetin.

\section{ABSTRAK}

Daun kopasanda (Chromolaena folium) kaya dengan flavonoid diantaranya adalah senyawa polifenol yang erat kaitannya sebagai zat yang mempunyai kapasitas antioksidan dalam menangkal radikal bebas. Polifenol dalam kopasanda diantaranya adalah katekin, epikatekin, prosianidin dan antosianidin. Kopasanda mengandung total fenol dan kapasitas antioksidan yang lebih tinggi dibandingkan anggur maupun teh. Sehingga dikatakan kopasanda memiliki kadar antioksidan cukup tinggi. Potensial total antioksidan dari sampel ditentukan oleh kemampuan mereduksi besi (Fe) sebagai ukuran "kekuatan antioksidan". Penelitan ini bertujuan untuk menguji aktivitas antioksidan serta kadar senyawa flavonoid pada daun kopasanda (Chromolaena folium), yang akan dianalisis dengan menggunakan metode FRAP. Pengujian FRAP melalui perubahan warna biru FeII senyawa tripyridyltriazine dari FeIII yang tidak berwarna yang bekerja menyumbangkan elektron. Metode ini banyak digunakan untuk menganalisis serta menenukan kadar antoksidan dan senyawa flavonoid pada suatu tumbuhan. Pada pengujian didapatkan hasil absorbansi dan konsentrasi standar kuarsetin sebagai standar untuk kadar antioksidan, dari hasil regresi linear didapatkan nilai rata-rata dari sampel ekstrak etanol daun kopasanda (Chromolaena folium) sebesar 16,914 mgQE/g ekstrak, artinya dalam setiap gram ekstrak setara dengan $16,914 \mathrm{mg}$ kuarsetin.

\section{ARTICLE INFO}

Keywords:

Kopasanda leaves; Quartz; Free Radical Antidote; FRAP method

\section{Pendahuluan}

Radikal bebas merupakan salah satu bentuk senyawa reaktif, yang secara umum diketahui sebagai senyawa yang memiliki elektron yang tidak berpasangan di kulit terluarnya (1). Radikal bebas berperan penting pada terjadinya arterosklerosis, penyakit jantung koroner, stroke, kanker, gagal ginjal, dan proses penuaan (2)(3).

Meskipun manusia juga dapat memproduksi senyawa-senyawa yang dapat berperan aktif dalam menanggulangi radikal bebas, seperti enzim SOD (superoksida dismutase), glutathione, dan katalase, namun jumlahnya seringkali tidak mencukupi, oleh sebab itu dibutuhkan asupan makanan yang banyak mengandung antioksidan dan flavonoid seperti vitamin C, E, betakaroten, maupun antioksidan fitokimia dari golongan fenolik, sehingga dapat melindungi dari serangan radikal bebas. Sumber antioksidan alami ini dapat diperoleh dari buah-buahan dan sayur-sayuran (2).

Salah satu tanaman yang banyak mengandung antioksidan dan flavonoid ditemukan dalam tumbuhan daun kopasanda (Chromolaena odorata.), salah satunya pada bagian daun. Penelitian 
sebelumnya terhadap ekstraksi daun kopasanda (Chromolaena odorata.) menunjukkan adanya aktivitas antioksidan yang tinggi dalam proses in vivo dan in vitro selain itu dalam daun kopasanda (Chromolaena odorata) yang kaya akan kandungan tannin, fenol, flavonoid, saponin, dan steroid (4).

Metode FRAP (Ferric Reducing Antioxidant Power) adalah salah satu metode yang secara langsung mengukur antioksidan dalam bahan. Benzie \& Strain mengemukakan bahwa metode FRAP adalah metode yang digunakan untuk menguji antioksidan dalam tumbuh-tumbuhan. Kelebihan metode FRAP ini yaitu metodenya murah, reagennya mudah disiapkan dan cukup sederhana dan cepat. Metode ini dapat menentukan kandungan antioksidan total dari suatu bahan berdasarkan kemampuan senyawa antioksidan untuk mereduksi ion $\mathrm{Fe}^{3+}$ menjadi $\mathrm{Fe}^{2+}$ sehingga kekuatan antioksidan suatu senyawa dianalogikan dengan kemampuan mereduksi dari senyawa tersebut (5).

Daun kapasanda dinyatakan sebagai bahan yang kaya dengan flavonoid diantaranya adalah senyawa polifenol yang erat kaitannya sebagai zat yang mempunyai kapasitas antioksidan dalam menangkal radikal bebas.Polifenol dalam kopasanda diantaranya adalah katekin, epikatekin, prosianidin dan antosianidin. Kopasanda mengandung total fenol dan kapasitas antioksidan yang lebih tinggi dibandingkan anggur maupun teh. Sehingga dikatakan kopasanda memiliki kadar antioksidan cukup tinggi (4).

Oleh karena itu penelitian ini dimaksudkan untuk dapat mengetahui kadar antioksidan yang terkandung dalam Daun Kopasanda dengan metode FRAP (Ferric Reducing Antioxidant Power) yang merupakan metode untuk mengukur kadar antioksidan dari suatu sampel ekstrak.

\section{Material dan Metode}

\section{Pengambilan sampel}

Sampel yang akan dianalisis dalam penelitian ini adalah daun Kopasanda (Chromolaena odorata) yang diperoleh dari daerah Pare-pare Sulawesi Selatan.

\section{Pengolahan Sampel}

Sampel daun Kopasanda (Chromolaena odorata) dibersihkan dari kotoran yang melekat pada daun menggunakan air mengalir lalu dikeringkan dengan cara diangin-anginkan. Setelah kering diblender, lalu siap untuk diekstraksi dengan metode maserasi.

\section{Ekstraksi}

Simplisia daun Kopasanda dalam bentuk serbuk sebanyak $300 \mathrm{~g}$ dimasukan kedalam wadah toples. Ditambahkan etanol 96\% hingga simplisia tersebut terendam, dibiarkan selama 3 hari dalam bejana tertutup dan terlindung dari cahaya sambil berulang-ulang diaduk. Setelah 3 hari simplisia disaring dan ampasnya direndam lagi dengan cairan penyari yang baru, hal ini dilakukan sebanyak 3 kali. Hasil penyarian yang didapat kemudian dikumpulkan dan diuapkan hingga diperoleh ekstrak etanol yang kental.

\section{Penyiapan pada sampel ekstrak etanolik}

Ekstrak etanol ditimbang dengan 3 replikasi yaitu masing-masing 5 mg. Masing-masing ekstrak dilarutkan dengan etanol 96\% sebanyak $5 \mathrm{~mL}$. kemudian dihomogenkan.

\section{Penyiapan Larutan Kurva Baku}

\section{a. Penyiapan Larutan Standar}

Larutan stok 1000 ppm dibuat dengan melarutkan 5 mg kuarsetin yang dilarutkan dengan etanol 96\% hingga batas labu ukur $5 \mathrm{~mL}$. Selanjutnya dari larutan stok $1000 \mathrm{ppm}$ dipipet 0,5 $\mathrm{mL}$ dimasukkan dalam labu takar $5 \mathrm{~mL}$ dengan etanol $96 \%$ hingga batas tanda (100ppm). Kemudian diambil masing-masing 0,3; 0,4; 0,5; 0,6; dan 0,7 $\mathrm{mL}$ dan ditempatkan dalam labu ukur $5 \mathrm{~mL}$ yang berbeda dan diencerkan dengan etanol 96\% hingga $5 \mathrm{~mL}$ dan dihomogenkan. Konsentrasi larutan standar 100 ppm asam askorbat yakni 6, 8, 10,12, dan 14 ppm. 


\section{b. Penyiapan Pada Larutan}

a) Larutan Dapar Fosfat 0,2 M pH 6,6

Larutan disiapkan dengan menimbang 2 gram $\mathrm{NaOH}$ dan dilarutkan dengan aquades bebas $\mathrm{CO}_{2}$ hingga tepat $250 \mathrm{~mL}$ dalam labu takar. Kemudian sebanyak 6,8 gram $\mathrm{KH}_{2} \mathrm{PO}_{4}$ yang dilarutkan dengan aquades bebas $\mathrm{CO}_{2} 250 \mathrm{~mL}$ dalam labu takar. Kemudian dipipet sebanyak 16,4 mL $\mathrm{NaOH}$ dimasukkan dalam labu takar dan dicampurkan $50 \mathrm{~mL}$ $\mathrm{KH}_{2} \mathrm{PO}_{4}$, selanjutnya diukur sampai pH 6,6 dan dicukupkan dengan aquades bebas $\mathrm{CO}_{2}$ hingga $200 \mathrm{~mL}$

b) Larutan Kalium Ferrisianida $1 \%$

Larutan disiapkan dengan melarutkan 1 gram kalium ferrisianida dalam aquades dan diencerkan dalam labu takar $100 \mathrm{~mL}$

c) Larutan $\mathrm{FeCl}_{3} \quad 0,1 \%$

Larutan disiapkan dengan melarutkan 0,1 gram $\mathrm{FeCl}_{3}$ dalam aquades dan diencerkan dalam labu takar $100 \mathrm{~mL}$

d) Larutan asam trikloroasetat (TCA) 10\%

Larutan disiapkan dengan melarutkan 10 gram TCA dalam aquades dan diencerkan dalam labu takar $100 \mathrm{~mL}$

\section{Uji Aktivitas Antioksidan dengan Metode FRAP}

Sebanyak 5 mg ekstrak dilarutkan dalam $5 \mathrm{~mL}$ etanol 96\%, lalu dipipet $1 \mathrm{~mL}$, ditambahkan $1 \mathrm{~mL}$ dapar fosfat $0,2 \mathrm{M}\left(\mathrm{pH}\right.$ 6.6) dan $1 \mathrm{~mL} \mathrm{~K}{ }_{3} \mathrm{Fe}(\mathrm{CN})_{6} 1 \%$ setelah itu,diinkubasi selama 20 menit dengan suhu $50^{\circ} \mathrm{C}$. Setelah diinkubasi ditambahkan $1 \mathrm{~mL}$ TCA lalu disentrifuge dengan kecepatan $3000 \mathrm{rpm}$ selama 10 menit. Setelah disentifuge dipipet $1 \mathrm{~mL}$ lapisan bagian atas kedalam tabung reaksi, dan ditambahkan $1 \mathrm{~mL}$ aquades dan $0,5 \mathrm{~mL} \mathrm{FeCl}_{3}$ 0,1\%. Larutan didiamkan selama 10 menit dan diukur absorbansinya pada $720 \mathrm{~nm}$.Sebagai blangko digunakan campuran larutan oksalat. Kurva kalibrasi dibuat menggunakan larutan kuarsetin dengan berbagai konsentrasi. Nilai FRAP dinyatakan dalam mg equivalen kuarsetin/gr ekstrak.

\section{Analisis Data}

Analisis data yang digunakan pada penentuan aktivitas antioksidan ekstrak etanol daun Kopasanda (Chromolaena odorata), dilakukan pada panjang gelombang maksimum 752,29 nm pada spektrofotometer UV-Vis sehingga didapatkan nilai berupa absorbansi. Setelah didapatkan nilai absorbansi maksimum, sampel kemudian dihitung total antioksidan dengan cara memasukkan dalam persamaan regresi kurva standar asam askorbat dengan persamaan linear $\mathrm{y}=\mathrm{bx}+\mathrm{a}$.

\section{Hasil dan Pembahasan}

Daun kapasanda dinyatakan sebagai bahan yang kaya dengan flavonoid diantaranya adalah senyawa polifenol yang erat kaitannya sebagai zat yang mempunyai kapasitas antioksidan dalam menangkal radikal bebas. Polifenol dalam kopasanda diantaranya adalah katekin, epikatekin, prosianidin dan antosianidin. Kopasanda mengandung total fenol dan kapasitas antioksidan yang lebih tinggi dibandingkan anggur maupun teh. (Alisi, dkk., 2011).

Pada penelitian ini dilakukan pengujian terhadap daun kopasanda yang bertujuan untuk menentukan kapasitas antioksidan yang ada dalam sampel ekstrak daun kopasanda. Dimana daun kopasanda ini diketahui memiliki kandungan flavonoid polifenol yang dapat berkhasiat sebagai antioksidan. Oleh karena itu dilakukan pengujian terhadap ekstrak daun kopasanda untuk memastikan kandungan flavonoid serta menentukan kadar flavonoid polifenol yang terdapat dalam ekstrak tersebut. 
Beberapa metode yang telah dikembangkan untuk mengukur aktivitas antioksidan suatu sampel salah satunya dengan menggunakan metode FRAP (Ferric Reducing Antioxidant Power). Pengujian FRAP telah digunakan untuk menentukan aktivitas antioksidan karena sederhana dan cepat serta metode ini dapat digunakan untuk mengukur kapasitas antioksidan yang terdapat dalam suatu ekstrak tanaman. Disamping itu, reaksi yang direproduksi linear yang berkaitan pada konsentrasi molar dari antioksidan dan reagen yang digunakan cukup sederhana serta tidak menggunakan alat khusus untuk menghitung total antioksidan.

Larutan standar yang digunakan adalah kuarsetin. Kuarsetin digunakan sebagai pembanding karena berfungsi sebagai antioksidan sekunder yaitu menangkap radikal bebas dan mencegah terjadinya reaksi berantai. Kuarsetin termasuk golongan antioksidan sekunder yang mampu menangkal berbagai radikal bebas ekstraseluler. Hal itu dikarenakan kuarsetin mempunyai gugus hidroksi bebas yang bertindak sebagai penangkap radikal bebas (6).

Pengukuran aktivitas antioksidan dari daun kopasanda menggunakan uji FRAP ini dengan larutan kuarsetin sebagai standar atau pembanding dalam penentuan kapasitas antioksidan. Penambahan dapar posfat pH 6,6 digunakan untuk mempertahankan keseimbangan $\mathrm{pH}$ dalam larutan. Adapun penambahan TCA bertujuan agar kompleks kalium ferrisianida mengendap. Penambahan $\mathrm{FeCl} 3$ juga bertujuan untuk membentuk kompleks berwarna hijau sampai biru (biru berlin). Daya reduksi merupakan indikator potensi suatu senyawa antioksidan. Daya reduksi dalam hal ini diukur dari kemampuan suatu antioksidan untuk mengubah $\mathrm{Fe}^{3+}$ menjadi $\mathrm{Fe}^{2+(6)}$.

Senyawa yang mempunyai daya reduksi kemungkinan dapat berperan sebagai antioksidan karena dapat menstabilkan radikal dengan mendonorkan elektron atau atom hidrogen sehingga senyawa radikal berubah menjadi lebih stabil.

Tabel 1. Hasil Pengukuran Absorbansi Larutan Standar Kuarsetin pada Panjang Gelombang $752,29 \mathrm{~nm}$

\begin{tabular}{ll}
\hline Konsentrasi (ppm) & Absorbansi $(\mathrm{y})$ \\
\hline 6 & 0,278 \\
\hline 8 & 0,378 \\
\hline 10 & 0,442 \\
\hline 12 & 0,555 \\
\hline 14 & 0,628 \\
\hline 16 & 0,752 \\
\hline
\end{tabular}

Pada pengukuran kadar antioksidan total dalam ektrak etanol daun kopasanda ini, menggunakan spektrofotometri UV-Vis karena memiliki panjang gelombang yang berkisar dari 380-780 nm. Digunakan alat instrumen tersebut untuk mendapatkan nilai absorbansi atau kadar antioksidan yang diperoleh dari hasil persamaan $\mathrm{y}=\mathrm{a}+\mathrm{bx}$. Adapun dari hasil running panjang gelombang untuk standar kuarsetin didapatkan absorbansi tertinggi pada panjang gelombang $752,29 \mathrm{~nm}$.

Tabel 2. Hasil Pengukuran Absorbansi Larutan Ekstrak Etanol Daun Kopasanda (Chromolaena odorata) pada Panjang Gelombang 752,29 nm

\begin{tabular}{lll}
\hline $\begin{array}{l}\text { Ekstrak Etanol Daun } \\
\text { Kopasanda (5 ppm) }\end{array}$ & $\begin{array}{l}\text { Absorbansi (y) } \\
752,29\end{array}$ & $\begin{array}{l}\text { Aktivitas Antioksidan } \\
\text { (mgK/g ekstrak) }\end{array}$ \\
\hline Replikasi 1 & 0,745 & 16,605 \\
\hline Replikasi 2 & 0,789 & 17,609 \\
\hline Replikasi 3 & 0,744 & 16,528 \\
\hline Rata-rata & & 16,914 \\
\hline
\end{tabular}


Pada analisis data untuk hasil absorban yang didapatkan, dilakukan perhitungan regresi dari konsentrasi (x) dengan nilai absorbansi (y) larutan pembanding kuarsetin diperoleh persamaan yaitu $\mathrm{y}=0,0438 \mathrm{x}+0,0177$ dengan nilai $\mathrm{R}^{2}=0,997$ dan untuk menghitung nilai aktivitas antioksidan dimasukkan nilai absorbansi sampel kedalam persamaan tersebut. Nilai FRAP dinyatakan dalam mg equivalen kuarsetin/gr ekstrak.

Hasil pengukuran absorbansi dan nilai aktivitas antioksidan ekstrak etanol daun kopasanda (Chromolaena odorata) tercantum pada table hasil penelitian sehingga didapatkan nilai ratarata dari sampel ekstrak etanol daun kopasanda (Chromolaena odorata) sebesar 16,914 $\mathrm{mgK} / \mathrm{g}$ ekstrak, artinya dalam setiap gram ekstrak setara dengan 16,914 mg kuarsetin.

\section{Kesimpulan}

Berdasarkan penelitian yang telah dilakukan, dapat disimpulkan bahwa:

1. Ekstrak etanol daun kopasanda (Chromolaena odorata) dapat digunakan sebagai penangkal radikal bebas (antioksidan).

2. Ekstrak etanol daun kopasanda memiliki aktivitas dalam menangkal radikal bebas dimana mengandung kadar flavonoid total $16,914 \mathrm{mgK} / \mathrm{g}$ ekstrak.

\section{Daftar Pustaka}

1. Winarsi H. Antioksidan Alami dan Radikal Bebas. Yogyakarta: Kanisus; 2007.

2. Kumalaningsih S. Antioksidan Alami. Surabaya: Trubus Agrisarana; 2006.

3. Youngson R. Antioksidan: Manfaat Vitamin C dan E Bagi Kesehatan, alih bahasa Susi Purwoko. Jakarta: Arcan; 2005.

4. Alisi C. Free Radical Scavenging and In-vitro Antioxidant Effects of Ethanol Extract of the Medicinal Herb Chromolaena odorata Linn. Br J Pharm Res. 2011 Jan 10;1:141-55.

5. Halvorsen BL, Holte K, Myhrstad MCW, Barikmo I, Hvattum E, Remberg SF, et al. A systematic screening of total antioxidants in dietary plants. J Nutr. 2002 Mar;132(3):461-71.

6. Kim J. Radical Scavenging Capacity and Antioxidant Activity of the E Vitamer Fraction in Rice Bran. J Food Sci. 2005 Apr 1;70:C208-13. 